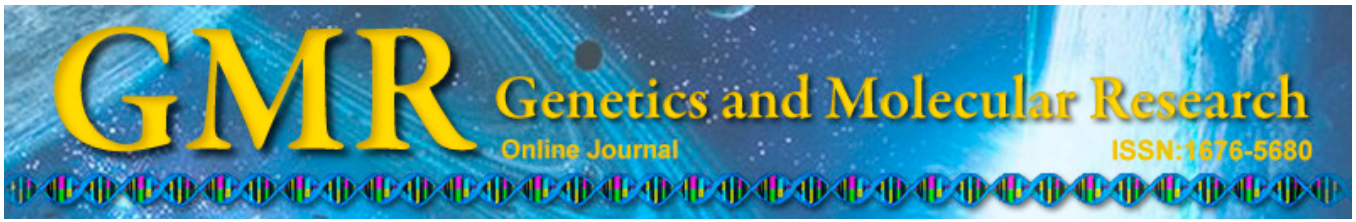

\title{
Association between polymorphisms in insulin-like growth factor-1 and risk of osteoporosis
}

\author{
W. Zhang, L.C. Zhang, H. Chen, P.F. Tang and L.H. Zhang \\ Department of Orthopaedics, General Hospital of Chinese PLA, Beijing, China \\ Corresponding authors: P.F. Tang / L.H. Zhang \\ E-mail: pftang301@126.com / zhanglihai1074@126.com
}

Genet. Mol. Res. 14 (3): 7655-7660 (2015)

Received September 12, 2014

Accepted February 4, 2015

Published July 13, 2015

DOI http://dx.doi.org/10.4238/2015.July.13.10

\begin{abstract}
We conducted a case-control study to assess the relationship between rs35767, rs2288377, and rs5742612 insulin-like growth factor-1 (IGF-1) and osteoporosis risk in a Chinese female population. The genotypes of rs35767, rs2288377, and rs5742612 of IGF-1 were determined by polymerase chain reaction-restriction fragment length polymorphism. Patients with osteoporosis were more likely to have drinking and smoking habits and have lower bone mineral density in the $\mathrm{L}_{2}-\mathrm{L}_{4}$ vertebrae, femoral neck, and total hip. According to conditional regression analysis, individuals carrying the TT genotype of rs 35767 had an increased risk of osteoporosis, with an adjusted odds ratio $(95 \%$ confidence interval) of 2.29 (1.35-4.97). In conclusion, our results suggest that the TT genotype of IGF-I rs35767 was associated with an increased risk of osteoporosis, suggesting that this polymorphism can be used as a predictive factor for osteoporosis risk.
\end{abstract}

Key words: Insulin-like growth factors; Osteoporosis; Polymorphism 


\section{INTRODUCTION}

Osteoporosis is a skeletal disease and is associated with a high risk of fracture (NIH, 2001). An estimated $55 \%$ of the population aged more than 50 years develops osteoporosis (NOF, 2008). Additionally, the incidence of osteoporosis has increased with increase in life expectancy. Previous studies showed that insulin-like growth factors (IGFs) play important roles in regulating the bone cell function because of their anabolic effects on the skeleton (McCarthy et al., 1989; Mohan, 1993). The main role of the IGF system in the local regulation of bone formation is to block basal bone cell proliferation (Mohan, 1993).

IGF-1 can regulate the size, shape, and composition of bones and also plays an important role in promoting osteoblast differentiation, mineralization, and proliferation in vitro (Zhang et al., 2012). However, a previous study found no significant association between IGF1 expression and bone mineral density (BMD) (Collins et al., 1998), and another study found no significant association between the levels of circulating IGF-1 and the risk of osteoporosis (Rosen, 2000). IGF-1 can be used as a mediator of various hormones, including growth hormone, estrogen, and parathyroid hormone, during bone metabolism in postmenopausal women (Yakar et al., 2002). Several single-nucleotide polymorphisms in IGF-1 are reported to play an important role in the risk of cancer, myopia, muscle function, and BMD regulation (Kostek et al., 2010). A previous study showed that rs35767, rs2288377, and rs5742612 of IGF-1 can influence the expression of IGF-1 (Zhao et al., 2007); however, few studies have investigated the association between single nucleotide polymorphisms in IGF-1 and the risk of osteoporosis in Chinese female populations. Therefore, we examined the relationship between rs35767, rs2288377, and rs5742612 in IGF-1 and the risk of osteoporosis in a Chinese female population.

\section{MATERIAL AND METHODS}

\section{Subjects}

In this case-control study, 428 patients with a primary diagnosis of osteoporosis were recruited from General Hospital of Chinese PLA between January 2011 and December 2013. A total of 428 age-matched healthy controls were selected from the health check-up center. All subjects who had other diseases or were taking drugs to influence skeletal homeostasis or interfere with bone metabolism were excluded from this study. All subjects signed an informed consent form for blood sample collection before participating in the study. The study protocol was approved by the ethics committee of the General Hospital of Chinese PLA.

\section{Measurement of BMD}

BMD was quantified using dual-energy X-ray absorptiometry (Hologic ${ }^{\circledR}$, Waltham, MA, USA) at the lumbar spine ( $\left.\mathrm{L}_{2}-\mathrm{L}_{4}\right)$, femoral neck hip, and total hip. BMD was assessed by dividing bone mineral content $(\mathrm{g})$ by bone area $\left(\mathrm{cm}^{2}\right)$, and the results were expressed as $\mathrm{g} / \mathrm{cm}^{2}$.

\section{Genotype analyses}

All study participants were asked to provide $5 \mathrm{~mL}$ peripheral venous blood, and blood 
samples were stored at $-20^{\circ} \mathrm{C}$ until analysis. Genomic DNA was extracted using the TIANamp DNA Blood Mini Kit (QIAGEN GmbH, Hilden, Germany) according to the supplier instructions. Polymerase chain reaction (PCR) primers were designed using the Primer Premier 5.0 software (Premier Biosoft International, Palo Alto, CA, USA). The genotypes of rs35767, rs2288377, and rs5742612 of IGF-1 were determined by PCR-restriction fragment length polymorphism (RFLP) according to manufacturer instructions. Each PCR for rs35767, rs2288377, and rs5742612 was conducted in a total volume of $20 \mu \mathrm{L}$, which included $50 \mathrm{ng}$ genomic DNA, $200 \mu \mathrm{M}$ dNTPs, 2.5 U Taq DNA polymerase (Promega, Madison, WI, USA), and $200 \mu \mathrm{M}$ primers. The PCR cycling program was as follows: denaturation at $95^{\circ} \mathrm{C}$ for $10 \mathrm{~min}$; followed by 40 cycles of $95^{\circ} \mathrm{C}$ for 30 $\mathrm{s}, 62^{\circ} \mathrm{C}$ for $30 \mathrm{~s}$, and $72^{\circ} \mathrm{C}$ for $30 \mathrm{~s}$; and final extension at $72^{\circ} \mathrm{C}$ for $10 \mathrm{~min}$. Approximately $5 \%$ of the samples were repeatedly genotyped, and the results were $100 \%$ concordant.

\section{Statistical analysis}

All statistical analyses were conducted using the STATA version 9.0 statistical software (StataCorp., College Station, TX, USA). Frequencies were used to describe the distribution of categorical variables and median and interquartile range was used for continuous variables. A standard chi-square test was used to assess deviation from Hardy-Weinberg equilibrium. The association between genetic polymorphisms and the risk of osteoporosis was estimated using a conditional multiple logistical regression model, and the results were expressed as the odds ratios and $95 \%$ confidence intervals. The odds ratio and $95 \%$ confidence interval were adjusted for potential risk factors, such as gender and age, smoking status, and drinking status. Statistical significance was defined as a 2-sided P value of less than 0.05.

\section{RESULTS}

\section{Patient demographic and clinical characteristics}

Demographic and clinical characteristics of the patients are shown in Table 1. The mean ages of patients with osteoporosis and controls were $59.5 \pm 7.1$ and $61.1 \pm 7.3$ years, respectively, at diagnosis. Among the 428 cases and 428 controls, $190(44.39 \%)$ were female and 238 (55.61\%) were male. Patients with osteoporosis were more likely to have drinking and smoking habits and have lower BMD in the $\mathrm{L}_{2}-\mathrm{L}_{4}$ vertebrae, femoral neck, and total hip.

The allele and genotype frequencies of rs35767, rs2288377, and rs5742612 in IGF-1, as determined by genotyping, in cases and controls are shown in Table 2. The genotype and allele distributions of rs 35767 , rs2288377, and rs5742612 in controls were in Hardy-Weinberg equilibrium. The genotype and allele distributions of the 3 single nucleotide polymorphisms in the osteoporosis patients and control subjects are shown in Table 2. According to conditional regression analysis, individuals carrying the TT genotype of rs35767 had an increased risk of osteoporosis, with adjusted odds ratio (95\% confidence interval) of 2.29 (1.35-4.97). However, no significant association was found between the rs2288377 and rs5742612 polymorphisms and risk of osteoporosis.

We conducted interaction analysis between the rs35767 polymorphism and demographics and BMD on the risk of osteoporosis. However, we found no significant interaction between the rs 35767 polymorphism and smoking and drinking status, and BMD of the $\mathrm{L}_{2}-\mathrm{L}_{4}$ vertebrae, femoral neck, and total hip. 
Table 1. Characteristics of cases and controls.

\begin{tabular}{|c|c|c|c|c|c|c|}
\hline Parameters & $\begin{array}{c}\text { Cases } \\
(\mathrm{N}=428)\end{array}$ & $\%$ & $\begin{array}{c}\text { Controls } \\
(\mathrm{N}=428)\end{array}$ & $\%$ & $\chi^{2}$ or t value & $P$ value \\
\hline Age & $60.5 \pm 7.1$ & & $61.1 \pm 7.3$ & & 1.22 & 0.11 \\
\hline \multicolumn{7}{|l|}{ Gender } \\
\hline Female & 190 & 44.39 & 190 & 44.39 & & \\
\hline Male & 238 & 55.61 & 238 & 55.61 & 1 & 0 \\
\hline \multicolumn{7}{|l|}{ Smoking } \\
\hline No & 232 & 54.21 & 267 & 62.38 & & \\
\hline Ever & 196 & 45.79 & 161 & 37.62 & 5.89 & 0.015 \\
\hline \multicolumn{7}{|l|}{ Drinking } \\
\hline No & 204 & 47.66 & 249 & 58.18 & & \\
\hline Ever & 224 & 52.34 & 179 & 41.82 & 9.5 & 0.002 \\
\hline \multicolumn{7}{|l|}{$\operatorname{BMD}\left(\mathrm{g} / \mathrm{cm}^{2}\right)$} \\
\hline $\mathrm{L}_{2}-\mathrm{L}_{4}$ vertebrae & $0.92 \pm 0.085$ & & $0.94 \pm 0.120$ & & 2.81 & 0.0025 \\
\hline Femoral neck & $0.615 \pm 0.042$ & & $0.636 \pm 0.048$ & & 6.81 & $<0.001$ \\
\hline Total hip & $0.624 \pm 0.055$ & & $0.652 \pm 0.038$ & & 8.67 & $<0.001$ \\
\hline
\end{tabular}

Table 2. Genotype and allele frequencies of IGF-1 and OR(95\%CI) for osteoporosis.

\begin{tabular}{|c|c|c|c|c|c|c|c|}
\hline IGF-I & & $\begin{array}{c}\text { Cases } \\
(\mathrm{N}=428)\end{array}$ & $\%$ & $\begin{array}{l}\text { Controls } \\
(\mathrm{N}=428)\end{array}$ & $\%$ & OR $(95 \% \mathrm{CI})^{\mathrm{a}}$ & $P$ value \\
\hline \multirow[t]{3}{*}{ rs35767 } & $\mathrm{CC}$ & 182 & 42.6 & 216 & 50.4 & 1.0 (Ref.) & - \\
\hline & $\mathrm{CT}$ & 193 & 45.1 & 186 & 43.5 & $1.23(0.92-1.65)$ & 0.15 \\
\hline & TT & 53 & 12.3 & 26 & 6.1 & $2.29(1.35-4.97)$ & 0.001 \\
\hline \multirow[t]{3}{*}{ rs 2288377} & AA & 349 & 81.6 & 365 & 85.2 & 1.0 (Ref.) & - \\
\hline & AT & 44 & 10.3 & 40 & 9.4 & $1.15(0.71-1.86)$ & 0.54 \\
\hline & TT & 35 & 8.1 & 23 & 5.4 & $1.59(0.89-2.88)$ & 0.09 \\
\hline \multirow[t]{3}{*}{ rs5742612 } & $\mathrm{CC}$ & 336 & 78.4 & 346 & 80.8 & 1.0 (Ref.) & - \\
\hline & $\mathrm{CT}$ & 48 & 11.3 & 42 & 9.7 & $1.18(0.74-1.88)$ & 0.47 \\
\hline & TT & 44 & 10.3 & 41 & 9.5 & $1.11(0.69-1.78)$ & 0.66 \\
\hline
\end{tabular}

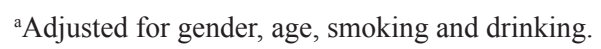

\section{DISCUSSION}

Osteoporosis is a serious health problem in older women. This disease is caused by multiple factors, including genetic and environmental factors (Harris et al., 2007; Abou-Raya et al., 2009; Zhang et al., 2014). Previous studies reported that genetic factors, such as the osteoprotegerin gene, CYP19, ESR1, vitamin D receptor, and LRP5, play a critical role in the development and pathogenesis of osteoporosis (Sun et al., 2014; Masi et al., 2014; Zhou et al., 2014; Al-Daghri et al., 2014). In our study, we found that the TT genotype of IGF-I rs35767 was correlated with the risk of osteoporosis.

IGF-1 has been reported to be associated with skeletal growth and plays an important role in promoting bone cell growth, differentiation, cell cycle progression, and preexisting bone cell activity (Yakar et al., 2002; Kostek et al., 2010). The expression and polymorphisms of IGF-1 are associated with BMD and the risk of osteoporosis (Morcov et al., 2012; Aliasgarzadeh et al., 2014; Elkazaz and Salama, 2014; Yun-Kai et al., 2014). Elkazaz and Salama (2014) reported that the level of IGF-1 was associated with BMD in premenopausal women. Jehle et al. (2003) reported that serum levels of IGF-1 and IGFBP-4 and IGFBP-5 were associated with osteoporosis. Morcov et al. (2012) found that IGF-1 was associated with BMD in pre- and postmenopausal women. Moreover, Yun-Kai et al. (2014) reported that the T allele 
of IGF-1 rs35767 was correlated with BMD and osteoporosis in a postmenopausal female population and that the rs 35767 polymorphism may be a marker for lower BMD and risk of osteoporosis. The results of this previous study were similar to our results. Further studies including a larger sample size are needed to confirm the results of our study.

There were several limitations to our study. First, it was conducted in a Chinese population and selected from one hospital, and thus selection bias may exist in our study. Second, we only analyzed the role of IGF-1 in the risk of osteoporosis; however, other genetic factors may influence the risk of osteoporosis and interaction may exist between genes. Third, because the sample size was limited, the statistical power was limited for identifying differences between groups. Further large sample size and multicenter studies are needed to confirm the association between IGF-1 polymorphisms and the risk of osteoporosis.

In conclusion, we found that the TT genotype of IGF-1 rs35767 was associated with osteoporosis risk, suggesting that IGF-1 rs35767 can be used as a predictive factor for determining the risk of osteoporosis. Further large sample size studies are needed to confirm the results of our study.

\section{REFERENCES}

Abou-Raya S, Helmii M and Abou-Raya A (2009). Bone and mineral metabolism in older adults with Parkinson's disease. Age Ageing 38: 675-680.

Al-Daghri NM, Al-Attas OS, Alkharfy KM, Khan N, et al. (2014). Association of VDR-gene variants with factors related to the metabolic syndrome, type 2 diabetes and vitamin D deficiency. Gene 542: 129-133.

Aliasgarzadeh A, Ghojazadeh M, Haji-Hoseini R, Mehanfar F, et al. (2014). Age related secretary pattern of growth hormone, insulin-like growth factor-I \& insulin-like growth factor binding protein-3 in postmenopausal women. Indian J. Med. Res. 139: 598-602.

Collins D, Woods A, Herd R, Blake G, et al. (1998). Insulin-like growth factor-I and bone mineral density. Bone 23: 13-16.

Elkazaz AY and Salama K (2014). The effect of oral contraceptive different patterns of use on circulating IGF-1 and bone mineral density in healthy premenopausal women. Endocrine 48: 272-8 [Epub ahead of print].

Harris TB, Launer LJ, Eiriksdottir G, Kjartansson O, et al. (2007). Age, gene/environment susceptibility-Reykjavik study: multidisciplinary applied phenomics. Am. J. Epidemiol. 165: 1076-1087.

Jehle PM, Schulten K, Schulz W, Jehle DR, et al. (2003). Serum levels of insulin-like growth factor (IGF)-I and IGF binding protein (IGFBP)-1 to -6 and their relationship to bone metabolism in osteoporosis patients. Eur. J. Intern. Med. 14: 32-38.

Kostek MC, Devaney JM, Gordish-Dressman H, Harris TB, et al. (2010). A polymorphism near IGF1 is associated with body composition and muscle function in women from the Health, Aging, and Body Composition Study. Eur. J. Appl. Physiol. 110: 315-324.

Masi L, Ottanelli S, Berni R, Cacudi E, et al. (2014). CYP19 and ESR1 gene polymorphisms: response of the bone mineral density in post-menopausal women to hormonal replacement therapy. Clin. Cases Miner. Bone Metab. 11: 36-43.

McCarthy TL, Centrella M and Canalis E (1989). Insulin-like growth factor (IGF) and bone. Connect. Tissue Res. 20: $277-282$.

Mohan S (1993). Insulin-like growth factor binding proteins in bone cell osregulation. Growth Regul. 3: 67-70.

Morcov C, Vulpoi C and Brănişteanu D (2012). Correlation between adiponectin, leptin, insulin growth factor-1 and bone mineral density in pre and postmenopausal women. Rev. Med. Chir. Soc. Med. Nat. Iasi. 116: 785-789.

NIH Consensus Development Panel on Osteoporosis Prevention, Diagnosis, and Therapy (2001). Osteoporosis prevention, diagnosis, and therapy. JAMA 285: 785-795.

National Osteoporosis Foundation (2008). Clinician's guide to prevention and treatment of osteoporosis. Washington, DC. Rosen CJ (2000). IGF-1 and osteoporosis. Clin. Lab. Med. 20: 591-602.

Sun T, Chen M, Lin X, Yu R, et al. (2014). The influence of osteoprotegerin genetic polymorphisms on bone mineral density and osteoporosis in Chinese postmenopausal women. Int. Immunopharmacol. 22: 200-203.

Yakar S, Rosen CJ, Beamer WG, Ackert-Bicknell CL, et al. (2002). Circulating levels of IGF-1 directly regulate bone growth and density. J. Clin. Invest. 110: 771-781.

Yun-Kai L, Hui W, Xin-Wei Z, Liang G, et al. (2014). The polymorphism of insulin-like growth factor-I (IGF-I) is related to osteoporosis and bone mineral density in postmenopausal population. Pak. J. Med. Sci. 30: 131-135. 
Zhang W, Shen X, Wan C, Zhao Q, et al. (2012). Effects of insulin and insulin-like growth factor 1 on osteoblast proliferation and differentiation: differential signalling via Akt and ERK. Cell. Biochem. Funct. 30: 297-302.

Zhang YD, Zhang Z, Zhou NF, Jia WT, et al. (2014). Association of the g.19074G $>$ A genetic variant in the osteoprotegerin gene with bone mineral density in Chinese postmenopausal women. Genet. Mol. Res. 13: 6646-6652.

Zhao J, Xiong DH, Guo Y, Yang TL, et al. (2007). Polymorphism in the insulin-like growth factor 1 gene is associated with age at menarche in caucasian females. Human Reprod. 22: 1789-1794.

Zhou PR, Liu HJ, Liao EY, Zhang ZL, et al. (2014). LRP5 polymorphisms and response to alendronate treatment in Chinese postmenopausal women with osteoporosis. Pharmacogenomics 15: 821-831. 